\title{
Financiamento Direto com Alienação Fiduciária em Garantia.
}

\author{
Sylvio Marcondes Machado \\ Professor Catedrático Jubilado de Direito Comercial da \\ Faculdade de Direito da Universidade de São Paulo

\begin{abstract}
SUMÅRIo: I. Introdução. II. Alienação fiduciária em garantia (2 elementos). III. Financiamento direto com alienação fiduciária em garantia (3 elementos). IV. Inexistência e nulidade; ineficácia. V Nulidade e anulabilidade. VI. Enquadramento da hipótese. VII. Situą̧ão dos coobrigados. VIII. A posição do avalista. IX. Argüição da nulidade.
\end{abstract}

\section{Introdução.}

1. O negócio fiduciário, que, provindo das fontes romanas, tem merecido, através do tempo, a constante atenção da doutrina, pode ser conceituado in genere, na sua concepção moderna, de acordo com OTTO DE SoUZA LIMA, o qual, compilando autores alienígenas e nacionais, conclui por propor a seguinte concisa definição: "Negócio fiduciário é aquele em que se transmite uma coisa ou direito a outrem, para determinado fim, assumindo o adquirente a obrigação de usar deles segundo aquele fim e, satisfeito este, de devolvê-los ao transmitente" ( $\mathrm{Ne}$ gócio Fiduciário, p. 160 a 170).

Estudando a atual evolução do negócio fiduciário, entre nós, observa PaUlo RestifFe Neto que - "Depois de várias décadas de prática de negócios fiduciários inominados, passou a legislação positiva pátria a viver a experiência da garantia fiduciária preceituada, sob a forma de cessão fiduciária de crédito (Lei de Estímulo à Indústria de Construção Civil) e alienação fiduciária (Lei de Mercado de Capitais e legislação de incentivo à expansão industrial). Ficou comprovada a superioridade desses institutos peculiares de garantia sobre as formas tradicionais, como instrumentos eficazes de segurança de crédito, com atuação destacada na política econômico-financeira desenvolvimentista concebida pela filosofia revolucionária em pleno curso" (Garantia Fiduciária, p. 21/22). 
Entretanto, não só a doutrina e a legislação especial têm cogitado do assunto. Sua crescente importância veio a alcançar os trabalhos de lege ferenda, como se vê da exposição de MIGUEL REALE, supervisor da Comissão Elaboradora e Revisora do Código Civil, a qual acompanha o Projeto de Código Civil, de iniciativa do Poder Executivo, ora em tramitação no Congresso Nacional. "De grande alcance prático é o instituto da propriedade fiduciária, disciplinado consoante proposta feita pelo Prof. JosÉ Carlos Moreira Alves, que acolheu sugestões recebidas do Banco Central do Brasil e analisou cuidadosamente ponderações feitas por entidades de classes " (. ), compendiado em artigos que "embora de maneira sucinta, compõem o essencial para a caracterização da propriedade fiduciária, de modo a permitir sua aplicação diversificada e garantida no mundo dos negócios" (Projeto de Lei n. ${ }^{\circ}$ 634, de 1975, Diário do Congresso Nacional, de 13-06-75, p. 122).

No campo do interesse despertado pela matéria, na "aplicação diversificada e garantida no mundo dos negócios", é que o presente estudo visa a examinar, em sua tipicidade, o negócio de "financiamento direto com alienação fiduciária em garantia". Dada a novidade do instituto em nosso Direito, parece aconselhável sejam as respostas, às questões que o tema suscita, precedidas de conceitos doutrinários atinentes à respectiva configuração, mediante formulação de hipótese para isso adequada, ou seja, de negócio no qual faltassem quaisquer dos elementos essenciais à sua constituição. Tal método, que permitirá abreviar aquelas respostas, inclui a consideração preliminar, na lição dos mestres, de algumas noções gerais, atinentes ao conteúdo dos negócios jurídicos e sua unidade ou complexidade, facilitando a determinação da natureza e dos efeitos do negócio em causa.

2. Tratando dos elementos do suporte fático do negócio jurídico, ensina Pontes De Miranda (Tratado de Direito Privado, v. 3). "No suporte fático do negócio jurídico, há elementos volitivos e elementos não-volitivos. Os elementos volitivos, sem os quais seria insuficiente o suporte fático, são os essentialia negotii ( . ) A distinção é entre essentialia e accidentalia negotii. Os naturalia negotii não concernem a classe que triparta os elementos volitivos do suporte fático. No seu conceito, só se alude aos efeitos não queridos, ou superfluamente queridos, e não a elementos do suporte fático. Enquanto a dicotomia (essentialia, accidentalia) exaure o que integra, como necessário, e o que vem a mais do que é o essencial (= necessário), a expressão naturalia negotii é pertinente ao plano da eficácia. 
Sem os essentialia negotii, o negócio não seria jurídico (= não entraria no mundo jurídico), ou seria outro negócio jurídico que aquele, a respeito do qual se procedeu à discriminação do essencial e do acidental ( . ) Assim, elementos volitivos do suporte fático são apenas os essentialia e os accidentalia negotii” ( $\left(258, n .^{\circ} 1\right)$. E, mais adiante, estudando, na mesma linha de pensamento, o conteúdo do ato jurídico, acrescenta: "São elementos essenciais dos negócios jurídicos, ou dos atos jurídicos stricto sensu, os que fazem os suportes fáticos serem negócios jurídicos ou atos jurídicos stricto sensu, ou serem certo tipo de negócio jurídico, ou de atos jurídicos stricto sensu. Se falta algum, não há o tipo de negócio jurídico, ou de ato jurídico stricto sensu (. .) Conteúdo necessário é o que a lei faz ser essencial à existência do negócio jurídico, ou do ato jurídico stricto sensu, ou ao tipo de negócio jurídico, ou de ato jurídico stricto sensu" ( $\$ 324$, n. $^{\circ} \mathrm{S} 2$ e 3 ).

E ROBERTO DE RUGGIERo, considerando a categoria geral e as categorias especiais do negócio jurídico, esclarece: "O negócio jurídico na sua mais abstrata figura, ou seja, como categoria geral que reúne numerosos tipos diversos (por exemplo: a compra-e-venda, a instituição de herdeiros, o repúdio a uma herança, etc.), consta de dois elementos fundamentais: uma declaração de vontade (ou mais, quando uma não baste para se atingir o fim em vista) e o próprio fim, isto é, a condição objetiva requerida pelo direito para dar atuação à vontade (...) Se esses dois são os requisitos indispensáveis do negócio jurídico concebido como categoria abstrata e universal, podem verificar-se, além deles, outros elementos nos vários tipos de negócio, já que cada tipo tem uma estrutura particular, que lhe dá uma individualidade própria e a diferencia de todos os outros. Ora, para cada um há elementos determinados, que constituem a sua essência e cujo concurso é necessário para que o negócio jurídico se constitua. Entre eles vem em primeiro lugar, como é natural, a declaração da vontade e, depois, a causa. Assim, na venda, são elementos constitutivos a coisa e o preço, no mútuo, a entrega de bens fungíveis; na doação, a forma do ato público. São os chamados essentialia negotii e a sua importância está no fato de, diante deles, parar a livre autonomia do cidadão; nenhum deles podia ser excluído, sob pena de se impedir a constituição do negócio" (Instituições de Direito Civil, tradução de ARY Dos SANTos, v. 1, p. 248/249).

3. Estabelecidos os elementos fundamentais, subjetivo e objetivo, do negócio jurídico, observe-se a unicidade e complexidade dos essentialia negotii, compendiando ensinamento do 
citado Pontes De MiRANDA, no referido volume do seu Tratado. "A unidade do contrato, ou de outro negócio jurídico, não pode ser em relação ao ato da conclusão, ou à instrumentação; nem ao conteúdo do negócio jurídico (seria unitariedade); nem à dependência recíproca das manifestações de vontade (há uniões de negócios jurídicos com dependência daquelas). $E \operatorname{sim} \mathrm{em}$ relação ao trato do negócio jurídico, dizendo-se também único o negócio jurídico ou contrato, quando há nele elementos de diferentes tipos de negócios jurídicos, inclusive de negócios jurídicos atípicos, suscetíveis de serem suporte fático de regras jurídicas especiais, mas subordinados à especificidade preponderante e ao fim comum do negócio jurídico completo (= misto)" (\$284, n. ${ }^{\circ} 2$ ). "Quando o negócio jurídico é único, mas complexo, não se pode dizer que é, em parte, contrato de compra-e-venda e, em parte, contrato de sociedade (por exemplo; é envoltório, cápsula, parte de elementos da compra-e-venda e parte de elementos da sociedade. Por isso mesmo, as regras jurídicas especiais que incidem sobre esses elementos não levam consigo a sua especificidade, se esses elementos não são os do caráter específico, preponderante, do negócio jurídico" (§ 286, n. ${ }^{\circ}$ 2). "As dependências são de muitas espécies, sugeridas pelas necessidades da vida. Não precisam ser explícitas, posto que se insiram, de ordinário, alusões ao outro negócio jurídico. Qualquer terminação, resolução (ou resilição), denúncia, rescisão, ou novação de um dos negócios jurídicos importa em terminação, resolução (ou resilição), denúncia, rescisão, ou novação do outro. A própria decretação de nulidade ou a anulação de um atinge o outro" (§ $\left.290, \mathrm{n}^{\circ}{ }^{\mathrm{2}} 2\right)$.

\section{Alienação Fiduciária em Garantia (2 elementos).}

4. O novel contrato foi admitido, em nosso Direito, como negócio jurídico típico, pela Lei $\mathrm{n}^{\circ}$ 4.728, de 14-07-65, que "disciplina o mercado de capitais e estabelece medidas para o seu desenvolvimento". Entre estas medidas foi incluída, no art. 66, a "alienação fiduciária em garantia".

Entretanto, instituto recém-criado, não se configurava com a nitidez à segurança dos negócios, que rapidamente se multiplicaram, e aconselhava a sua reformulação, levada a efeito pelo dec.-lei $n .^{\circ}$ 911, de $1 .^{\circ}-10-69$, assim justificado na respectiva exposição de motivos. "A importância crescente do crédito ao consumidor está exigindo uma reformulação do Instituto da Alienação Fiduciária, que passou a desempenhar função relevante como garantia nas operações feitas pelas financeiras para fi- 
nanciamento ao usuário de bens de consumo ou de produção (...) Instituto novo, introduzido no Direito brasileiro pelo art. 66 da Lei n. ${ }^{\circ} 4.728$, de 14-07-1965 (Lei do Mercado de Capitais), a alienação fiduciária não tinha merecido, até o presente momento, uma adequada regulamentação processual ( ...) Introduzindo as alterações que se fazem mister nas linhas mestras da legislação sobre mercado de capitais, o anexo projeto de decreto-lei leva em conta a experiência acumulada durante cerca de quatro anos no campo da alienação fiduciária e fará com que cessem as dúvidas surgidas nos tribunais em virtude das lacunas existentes na legislação vigente, que fixou as normas substantivas, mas não cuidou das adjetivas, vale dizer, da regulamentação do rito processual."

5. Das normas substantivas, da emenda legislativa, sobressai, desde logo, a do art. $1 .^{\circ}$, substitutiva do texto do art. 66 , da Lei n. ${ }^{\circ} 4.728$, de 1965 , o qual passou a ter a seguinte redação:

"Art. 66. A alienação fiduciária em garantia transfere ao credor o domínio resolúvel e a posse indireta da coisa móvel alienada, independentemente da tradição efetiva do bem, tornando-se o alienante ou devedor em possuidor direto e depositário, com todas as responsabilidades e encargos que lhe incumbem de acordo com a lei civil e penal".

$\mathrm{Na}$ clareza de sua nova redação, o art. 66 integra, no conceito da alienação em garantia, dois elementos indispensáveis: a) uma relação obrigacional, entre o alienante (devedor) e o adquirente (credor); b) uma relação real, pela transferência de domínio (embora limitado), daquele, para este. Conforme explicitado, sem discrepância, por nossos monografistas.

6. Analisando o instituto, esclarece PAULo Restiffe Neto. "Encerra em sua unidade dois elementos distintos: um de ordem obrigacional (do devedor) relacionado com o pagamento da dívida decorrente do financiamento; e outro de direito real, consistente na alienação da coisa, que se transfere ao financiador em garantia do cumprimento da obrigação de pagar toda a importância final do financiamento. No negócio fiduciário (gênero) a relação de direito real situa-se no recebimento da coisa e o cunho obrigacional está ligado ao dever de sua restituição ao transmitente, ao passo que na alienação fiduciária em garantia, enquanto o elemento real guarda o mesmo cunho do negócio fiduciário (transmissão da coisa), o elemento obrigacional, por sua vez, encontra-se também com o devedor e 
traduz-se na obrigação de pagar a dívida na forma e prazo avençados. Só depois de satisfeita esta condição, com a desoneração do devedor pelo integral pagamento da dívida, extingue-se a obrigação e o contrato, e surge, por via de conseqüência, a restituição ao status quo ante, reingressando a coisa no patrimônio do fiduciante" (Garantia Fiduciária, p. 90).

ORLANDO GOMES repara que "a preferência por esta expressão (alienação) em vez de 'venda para garantia', já indica inclinação por uma das soluções do problema da natureza dessa espécie jurídica. Admitiu o legislador a configuração de um contrato autônomo translativo da propriedade, para garantia de uma relação obrigacional". E mostrando a congênita ligação entre as duas ordens de relação jurídica, pondera. "Da alienação fiduciária em garantia originam-se para as partes direitos e obrigações interdependentes, que se projetam em planos distintos. Porque encerra negócio translativo e negócio obrigacional, regulam-se seus efeitos, que se completam, em setores diversos do Direito Civil, aplicando-se-lhe regras próprias do direito de propriedade e do direito de crédito. Em síntese, possui simultaneamente eficácia real e pessoal. No seu aspecto de negócio translativo, traduz o exercício do poder de disposição dos bens, importando imediata e direta alteração da preexistente situação patrimonial, patenteada na aquisição e conseqüente perda do direito de propriedade. No seu aspecto de negócio obrigacional, compreende pretensões e obrigações, entrelaçadas com a situação jurídico-real, que consubstanciam a relação débito-crédilto" (Alienação Fiduciária em Garantia, p. 74, nota, e 83).

7. Aliás, antes mesmo da nova e melhor redação do citado art. 66, a do decreto-lei n. ${ }^{\circ}$ 911, ALFREDo BUZAID, examinando-o, no primitivo texto da Lei n. ${ }^{\circ} 4.728$, já escrevera. "O art. 66 da Lei n. ${ }^{\circ} 4.728$ estabelece: 'Nas obrigações garantidas por alienação fiduciária de bem móvel, o credor tem o domínio da coisa alienada, até a liquidação da dívida garantida'. A alienação fiduciária em garantia é, nos expressos termos desta definição legal, um negócio jurídico uno, posto que objetivamente complexo. Compõe-se de duas relações jurídicas: uma obrigacional, outra real. A primeira se expressa numa dívida, que é - negócio causal. A segunda numa garantia, que é o ato de alienação. O nexo que se forma entre elas supõe a um tempo o financiamento e a transferência ao credor de um bem que, uma vez satisfeita a obrigação, deve ser restituído ao alienante" (Revista dos Tribunais, março de 1969, v. 401, p. 19). 


\section{Financiamento Direto com Alienação Fiduciária em Garantia (3 elementos).}

8. Entretanto, aos elementos, já deduzidos pela doutrina, do cogitado art. 66, integrativos da "alienação fiduciária em garantia" ( ${ }^{\circ}{ }^{\circ} 4$ a 7 supra), há de ser acrescentado outro, também de direito cogente, quando se trate de "financiamento direto com alienação fiduciária em garantia”.

Realmente, tratando-se de operação de "financiamento", é preciso não esquecer que a Lei $n^{\circ}{ }^{\circ} 4.595$, de 11-12-64 (Reforma Bancária), dispondo que compete privativamente ao Conselho Monetário Nacional disciplinar o crédito em todas as suas modalidades e as operações creditícias em todas as suas formas, inclusive aceites, avais e prestações de quaisquer garantias por parte das instituições financeiras (art. $4 .^{\circ}, \mathrm{n} .0^{\circ} \mathrm{VI}$ ) determinar que "compete ao Banco Central da República do Brasil cumprir as disposições que lhe são atribuídas pela legislação em vigor $e$ as normas expedidas pelo Conselho Monetário Nacional" (art. 9. $\left.{ }^{\circ}\right)$. E o Banco Central, no exercício dessas atribuições, "com o propósito de regulamentar as operações realizadas pelas Sociedades de Crédito e Financiamento", baixou, em 30-12-66, a Resolução $n .^{\circ} 45$, em cujo item $n .^{\circ} I V$, estabeleceu:

"O financiamento da compra contratada diretamente com o consumidor ou usuário final terá por garantia principal a alienação fiduciária do bem objeto da transação e não poderá exceder $80 \%$ do valor da venda."

9. Em conseqüência, quando se trata de operação de $f i$ nanciamento direto, "realizada por Sociedades de Crédito e Financiamento", a relação real e a relação obrigacional, próprias do instituto, como acaba de ser demonstrado, gravitam em torno de um terceiro elemento, igualmente imperativo, expresso na exigência de que 0 financiamento direto ao consumidor "terá, por garantia principal" a alienação fiduciária. O que, nessa modalidade de operação, torna o instituto mais complexo, acentuando-lhe a tipicidade, sem prejuízo, todavia, da sua unidade e indivisibilidade.

10. Em verdade, esses três elementos se realçam e conjugam na observação da doutrina ( $\mathrm{n}^{\circ} 2$ supra), já que são elementos essenciais dos negócios jurídicos os que fazem os suportes fáticos serem negócios jurídicos, ou certo tipo de negócio jurídico. Se falta algum, não há o tipo de negócio juri- 
dico. Conteúdo necessário é o que a lei faz ser essencial à existência do negócio jurídico ou ao tipo de negócio jurídico (PoNTES DE MIRANDA). Cada tipo de negócio jurídico tem uma estrutura particular que lhe dá uma individualidade própria e a diferencia de todos os outros; para cada um há elementos determinados, que constituem a sua essência e cujo concurso é necessário para que o negócio jurídico se constitua. São os chamados essentialia negotii e a sua importância está no fato de, diante deles, parar a livre autonomia do cidadão; nenhum deles podia ser excluído, sob pena de se impedir a constituição do negócio" (RUGGIERo).

Ademais (.$^{\circ} 3$ supra), a unidade do contrato, ou de outro negócio jurídico não pode ser em relação ao ato da conclusão e, sim, em relação ao trato do negócio jurídico, dizendo-se também único o negócio jurídico ou contrato, quando há nele os elementos de diferentes tipos de negócios jurídicos, mas subordinados à especificidade e ao fim comum do negócio jurídico complexo (PonTEs DE MiRANDA).

11. Se essa é a natureza jurídica do "financiamento direto com alienação fiduciária em garantia" - cuja existência depende da concorrência simultânea dos três elementos essenciais, que o fazem negócio uno e complexo - poderá produzir algum efeito contrato apenas rotulado dessa designação, mas ao qual faltem quaisquer dos ditos elementos?

\section{Inexistência e Nulidade; Ineficácia.}

12. Considerando que a eficácia do negócio jurídico depende de sua validade, mas esta, por sua vez, pressupõe-lhe a existência, o problema se coloca na distinção entre a inexistência e a nulidade, de que resultará a ineficácia do negócio em exame. Problema suscitado, na doutrina, ensejará resposta exaustiva à questão.

Propondo a distinção, CaIo Mário Da Silva PereIra entende que - Negócio jurídico inexistente é aquele a que falta um pressuposto material de sua constituição. Não é o mesmo que nulidade, porque no ato nulo estão presentes os pressupostos de fato, em virtude dos quais o ato chega a formar-se, porém frustro nos resultados, dada a contravenção de alguma disposição de ordem pública (...) Quando o objeto é ilícito ou impossível, o ato é nulo; mas se inexiste objeto, será inexistente o ato. São hipóteses diferentes, pois em um caso objeto existe, 
mas a relação jurídica deixa de se constituir por sua afronta à lei, à moral, aos bons costumes, ou por ser aquele inatingível; no outro caso, não se forma o ato, por ausência total de objeto" (Instituições de Direito Civil, v. I, p. 453).

Todavia, o própria autor assinala opinião contrária, esclarecendo - "MAZEAUD et MAZEAUD, Leçons, I, p. 356, opinam contrariamente à especialização dos atos inexistentes, teoria que consideram, não apenas inútil, mas falsa mesmo. Tudo que a configuração da inexistência oferece, entendem eles que já o conceito de nulidade dá; e que não é possível aceitar as conseqüências que se costumam tirar, como seja a imprescritibilidade, a obtenção sem pronunciamento judicial, etc." (ob. e v. cits., nota à p. 452).

Já ORLANDo Gomes, na Introdução ao Direito Civil, é mais explícito na sua observação e contradita. "A teoria da inexistência dos atos jurídicos é uma construção doutrinária que se não cristalizou ainda na dogmática jurídica em razão da resistência que lhe oferecem grandes nomes, impedindo a sua consagração legal. Continua a ser objeto de polêmica" (p. 348). E após analisar as teses divergentes, prossegue - "Tais objeções abalam a teoria da inexistência. Proclama-se, modernamente, a sua inutilidade. Do ponto de vista prático, é indiferente que o obstáculo à eficácia de um ato jurídico seja de ordem natural du legal. Em qualquer hipótese, não produzirá efeitos. Demais disso, o ato inexistente, por mais absurdo que seja, é uma aparência de ato. Essa aparência precisa ser desfeita, o que se há de verificar, necessariamente, mediante pronunciamento judicial, a despeito da opinião dos partidários da teoria. $O$ ato inexistente equivalerá, portanto, ao ato nulo, ainda sob esse aspecto prático. Se doutrinariamente é admissível a distinção entre inexistência e nulidade, praticamente não tem utilidade. A lei não pode admitir a categoria dos atos inexistentes, porque são simples fatos sem ressonância jurídica, dos quais, logicamente, não deve ocupar-se. A jurisprudência se tem mostrado infensa à sua aceitação, inclusive porque pode conduzir a conseqüências inadmissíveis, como a conversão de um contrato em outro por falta de objeto" (p. 350-351).

13. Em conseqüência: se negócio jurídico inexistente é aquele a que falta um pressuposto material de sua constituição, ao passo que o ato nulo existe, mas é frustro nos resultados (CAIO MARIO) ; se tudo que a configuração da inexistência oferece, já o conceito de nulidade dá (MAZEAUD et MAZEAUD); se 
é indiferente que o obstáculo à eficácia de um ato jurídico seja de ordem natural ou legal, pois, em qualquer hipótese, não produzirá efeitos, e o ato inexistente equivalerá, portanto, ao ato nulo (ORLANDo GOMES) - resulta irretorquível que, na hipótese indagada, seja à luz da teoria da inexistência, seja sob o comando imperativo da lei, o negócio é ineficaz.

\section{Nulidade e Anulabilidade.}

14. Face ao nosso Código Civil. a demonstrada ineficácia de negócio de "financiamento direto com alienação fiduciária em garantia" - na hipótese de que lhe faltem quaisquer dos elementos essenciais, integrativos da tipicidade do instituto resultará da sua nulidade (art. 145), ou da sua anulabilidade (art. 147) ? É absoluta, ou é relativa?

Pontes De Miranda, examinando a técnica do nosso Direito, mostra o caminho e justifica solução acertada. "O Código Civil, no art. 145, II, referiu-se ao ilícito, sem o definir. Já antes aludira ao lícito (art. 82). Pergunta-se: ilícito no art. 145, n. ${ }^{\circ}$ II, é somente o contra a lei, ou é o contra a lei e a moral, ou somente contra a moral? (.) A concepção brasileira do "objeto ilícito" (art. $145,{ }^{\circ}{ }^{\circ}$ II, $1 .^{a}$ parte) de modo nenhum deixa ao juiz margem a consultar o seu íntimo, para dizer se o objeto (ou o fim) é imoral". Em seguida, estudando o "fundamento e natureza da nulidade por ilicitude", esclarece - "A ilicitude nulificante limita a autonomia da vontade. O legislador poderia, de lege ferenda, adotar: a) a técnica $d a$ insuficiência do suporte fático (= não entraria no mundo jurídico), nihil actum est (...); b) a técnica da deficiência do suporte fático, resultando dela a existência e nulidade (no sentido moderno) do negócio jurídico (e.g., art. 145, II) ; c) a técnica da deficiência do suporte fático, resultando apenas a anulabilidade." E considerando que o Código Civil adotou, no art. $145, n .{ }^{\circ}$ II, a técnica indicada sob a letra "b", conclui "A nulidade é o que mais consulta os interesses gerais e dos. figurantes, porque, não vedando a entrada do suporte fático no mundo jurídico, evita que faça depender de verificação in casu a resposta à questão da existência ou inexistência, e, negando-lhe efeitos desde logo e concebendo como nulo, e não só anuilável, o negócio jurídico, permite a alegabilidade pelos interessados, quaisquer, e de ofício. Constitui, portanto, aquisição técnica de primeira ordem a classificação do ilícito como causa de nulidade" (Tratado de Direito Privado, v. 4, p. 145, 146 e 151/152). 


\section{Enquadramento da Hipótese.}

15. Procurando estabelecer as linhas doutrinárias que informam o assunto, o presente estudo relembrou, na introdução, noções gerais, pertinentes aos essentialia negotii cujo concurso é indispensável, para que se constitua o negócio jurídico - e à sua unicidade, quando complexo (ns. 2 e 3 supra) ; fixou os elementos, de direito real e de direito obrigacional, que tipificam a "alienação fiduciária em garantia" (ns. 4 a 7 supra) ; evidenciou o terceiro elemento, o da garantia principal, que a eles a lei acresceu, no negócio de "financiamento direto com alienação fiduciária em garantia" (ns. 8 a 11 supra); determinando a natureza jurídica do instituto e seus elementos essenciais, cogitou da ineficácia, fosse por inexistente, fosse por nulo (ns. 12 e 13 supra); demonstrou que, em o nosso Direito, a nulidade se firma na ilicitude do objeto, conforme o disposto no art. 145, II, do Código Civil.

Tudo, entretanto, foi desenvolvido em torno de uma hipótese - a de financiamento direto com alienação fiduciária em garantia, em negócio a que faltassem quaisquer dos elementos essenciais à sua constituição. Hipótese, como de início se disse, destinada a simplificar sua correta solução, face às leis vigentes, agora esclarecidas pelo ensinamento da doutrina.

16. Em conseqüência: se negócio jurídico inexistente é aquele a que falta um pressuposto material de sua constituição; mas se tudo que a configuração da inexistência oferece, já o conceito da nulidade dá; e se o conceito de ato inexistente equivale ao de ato nulo (ns. 12 e 13 supra) resulta irretorquível que, naquela hipótese, o negócio é ineficaz.

Ineficácia que decorre diretamente da ilicitude do negócio, contratado contra a lei, e, pois, sob a sanção estabelecida no Código Civil, cujo art. $145,{ }^{\circ}{ }^{\circ} \mathrm{II}, 1 .^{\mathrm{a}}$ parte, dispõe: “É nulo o ato jurídico quando for ilícito o seu objeto". Preceito onde "constitui aquisição técnica de primeira ordem a classificação do ilícito como causa de nulidade" (n. ${ }^{\circ} 14$ supra).

17. Ademais, essa conclusão se confirma na jurisprudência de nossa Segunda Instância.

Resolvendo sobre o negócio fiduciário, considerado in genere, julgou o Tribunal de Justiça de São Paulo:

"Perante o direito nacional, cumpre adimitir-se como válido o negócio fiduciário, desde que as partes sejam capazes, o objeto lícito e não haja forma prescrita ou não defesa em lei" (Rev. Tribs., v. $382 / 160)$. 
Ainda do mesmo Tribunal:

“E válido o negócio fiduciário desde que, través dele, não se desrespeite a lei, nem se venha causar prejuízo a terceiro" (Rev. Tribs., v. $402 / 135)$.

$\mathrm{E}$ passando do gênero à espécie, do financiamento com alienação fiduciária em garantia, decidiu o $20^{\circ}$ Tribunal de Alçada Civil:

"Quando no negócio sob alienação fiduciária deixam de existir seus pressupostos, o contrato é nulo como tal".

"Desnaturada a alienação fiduciária, não se justifica a prisão do depositário infiel, contra o qual somente se legitimam medidas oriundas desse negócio fiduciário com todos os seus "essentialia" (Rev. Tribs., v. 459/176).

\section{Situação dos Coobrigados.}

18. Em prosseguimento, admita-se que na suscitada hipótese figurassem, ao lado da garantia principal, pela alienação fiduciária dos bens fianciados, outras garantias acessórias, como caução, hipoteca, fiança ou aval, prestados por terceiros.

Ora, se faltam ao imaginado contrato elementos essenciais à sua tipificação como negócio jurídico que a lei fez uno $e$ complexo; se a doutrina sustenta a sua nulidade por ilicitude do objeto; se a jurisprudência entende que o negócio fiduciário é válido se tiver objeto lícito, ou não se desrespeite a lei, mas, ao contrário, é nulo, se deixam de existir seus pressupostos, ou não se apresente com todos os seus essentialia - qual a validade das mencionadas garantias acessórias?

19. A questão se coloca face ao art. $\mathbf{1 5 3}$ do Código Civil, in verbis:

“Art. 153. A nulidade parcial de um ato não o prejudicará na parte válida, se esta for separável. A nulidade da obrigação principal implica a das obrigações acessórias, mas a destas não induz a da obrigação principal."

Compreende a norma, portanto, duas partes: na $1 .^{\mathrm{a}}$, se cogita da indivisibilidade do negócio; na $2 .^{\mathrm{a}}$, da percussão do negócio principal, sobre o acessório. 


\section{Quanto à $1 .^{2}$ parte, leciona Pontes DE Miranda:}

"Negócio jurídico uno e o art. 153 - Se o negócio jurídico é um só (unidade) os diferentes acordos ou convenções, que lhe integram o suporte fático, são elementos desse (...). Sendo unidade o negócio jurídico, a 'parte separável' de que fala o art. 153 supõe não-existência da relação econômica, ou moral, inserta no suporte fático, que imponha o interesse só no todo. Se esse interesse existe e, pois, aquela relação econômica, ou moral, as 'partes' do negócio jurídico são inseparáveis: o défice de uma é défice de todas" (Tratado, v. 3, p. 188).

Quanto à $2 .^{a}$ parte, veja-se o ensinamento de Messineo:

"Contrato principal e acessório - É uma distinção de conteúdo óbvio; ela toma como ponto de partida o fato de que um contrato dependa lógica e juridicamente de outro como de uma premissa indispensável (contrato acessório, do qual podem constituir exemplos os contratos de garantia : o penhor, a hipoteca voluntária, a fiança e similares (. . . ). O contrato acessório segue a sorte do contrato principal, especialmente com respeito à nulidade, à possibilidade de resolução e a outros efeitos semelhantes" (Francesco MEssineo, Doctrina General del Contrato, na tradução argentina de FonTANARRosa e outros, tomo I, p. $427 / 428)$.

20. Em conseqüência, não sendo o negócio suscitado composto de "partes separáveis", pois todas são elementos essenciais ao tipo estabelecido na lei, não se podendo, portanto, pensar em nulidade parcial (art. $153,1 .^{\mathrm{a}}$ parte) ; recaindo, ademais, a nulidade, na obrigação principal, com repercussão sobre as obrigações acessórias (art. 153, 2. ${ }^{\mathrm{a}}$ parte) - há de se concluir pela nulidade, não só do negócio principal (ns. 16 e 17 supra), como, também, das garantias acessórias, em que se situassem os respectivos coobrigados.

\section{A Posição do Avalista.}

21. Dada a natureza própria dos títulos de crédito, considere-se, em especial, a situação de eventual avalista, de títulos representativos do financiamento.

Rejeite-se, de pronto, entre as partes, qualquer idéia de autonomia desses títulos, pois, dispensando elucubrações des- 
necessárias, é suficiente observar que a literalidade de tais títulos estará vinculada à literalidade do contrato que lhes deu causa.

22. Registre-se, isso sim, a importância do $3 .^{\circ}$ elemento (n. ${ }^{\circ} 9$ supra), já acima evidenciado no texto do item IV, da Resolução n. ${ }^{\circ} 45$, do Banco Central, para tipificar o "financiameto direto com alienação fiduciária em garantia", negócio em que o legislador acrescentou, à relação real (1.0 elemento) e à relação obrigacional $\left(2 .^{\circ}\right.$ elemento), a exigência de que o financiamento direto ao consumidor "terá, por garantia principal a alienação fiduciária”.

Realmente, aqui se aprofunda o sentido da norma, que revela um duplo efeito. De um lado, pela alienação, acautela - credor fiduciário; de outro, por ser a garantia principal, acautela as abonações acessórias, inclusive do avalista. E os direitos de natureza real incrustados na coisa alienada visam menos ao benefício do credor - que poderia executar qualquer das garantias - do que, especialmente, à proteção dos abonadores. Na verdade, se o avalista pagar e não existir, por exemplo, a garantia principal da coisa tida por alienada fiduciariamente, fica frustrado o direito que a lei lhe confere de se sub-rogar nos direitos do credor sobre a mesma coisa. Civil:

23. A sub-rogação legal acha-se estabelecida no Código

Art. 985 - A sub-rogação opera-se, de pleno direito, em favor:

III - Do terceiro interessado, que paga a dívida pela qual era ou podia ser obrigado, no todo ou em parte."

Art. 988 - A sub-rogação transfere ao novo credor todos os direitos, ações, privilégios e garantias do primitivo, em relação à dívida, contra o devedor principal e os fiadores."

Não obstante a clareza dos textos, o legislador julgou adequado explicitá-los, na matéria de "financiamento com alienação fiduciária em garantia", a fim de evitar quaisquer dúvidas sobre as seguranças do novel instituto, dispondo no art. $6 .^{\circ}$, do citado Dec.-Lei n. ${ }^{\circ}$ 911, de $1 .^{\circ}-10-69$ :

"Art. $6 .^{\circ}$ - O avalista, fiador ou terceiro interessado que pagar a dívida do alienante ou devedor, se sub-rogará, de pleno direito, no crédito e na garantia constituída pela alienação fiduciária" 
24. Mas não é somente o art. $6 .^{\circ}$ do Dec.-lei n. ${ }^{\circ} 911$, que, através da sub-rogação, assegura ao avalista a garantia do bem alienado fiduciariamente. Também no seu art. $3 .^{\circ}, \S 5 .^{\circ}$, avulta o significado do "duplo efeito" produzido pela garantia fiduciária. Veja-se a lição de PaUlo Restiffe Neto, em sua obra, antes citada, Garantia Fiduciária:

"Por força do $\S 5 .^{\circ}$ do art. $3 .^{\circ}$ do Decreto-lei n. ${ }^{\circ}$ 911, a sentença proferida nos autos da ação de busca e apreensão "consolidará a propriedade e posse plena e exclusiva nas mãos do proprietário fiduciário", exatamente para poder este proceder à venda da coisa."

"Dessa decisão decorrem vários efeitos jurídicos: 1) consolidação da propriedade e posse plena e exclusiva do bem em mãos do credor, obrigado à venda de excussão; 2) formalização da rescisão do contrato; 3) frustração, para os coobrigados, da possibilidade de sub-rogação de pleno direito no objeto da garantia; 4) desobrigação dos avalistas e fiadores; ( .) E. já não sendo possível aos coobrigados sub-rogarem-se na garantia, porque o próprio credor se antecipou em excuti-la, desaparece a responsabilidade originariamente líquida e certa que lhes correspondia. Isto significa que a responsabilidade dos coobrigados é correlata ao direito assegurado de sub-rogação na garantia, de modo que aquela subsiste na medida em que esta possa ser exercitável" (p. 186/187).

25. Entrelaçam-se, assim, num nó indesatável, o item IV, da Resolução n. ${ }^{\circ} 45$, o art. $6 .^{\circ}$, do Dec.-lei. n. ${ }^{\circ} 911$, e o $\S 5 .^{\circ}$, do art. $3^{\circ}$, do mesmo diploma, cuja interpretação conjugada elucida a posição do avalista, no negócio ora cogitado.

Preceitos que, todos de ordem pública, se burlados, reforçam, em relação ao avalista de títulos representativos do financiamento, a conclusão já alcançada (ns. 16 a 20 supra) da nulidade, não só do negócio principal, como, também, das garantias acessórias.

\section{Argüição da Nulidade.}

26. O Código Civil, após discriminar, nos incisos I a $\mathrm{V}$, do art. 145, os casos em que "é nulo o ato jurídico", determina em seu art. 146:

"Art. 146 - As nulidades do artigo antecedente podem ser alegadas por qualquer interessado, 
ou pelo Ministério Público, quando lhe couber intervir.

Parágrafo único - Devem ser pronunciados pelo Juiz, quando conhecer do ato ou dos seus efeitos, não lhe sendo permitido supri-las ainda a requerimento das partes."

Analisando a norma, esclarece a doutrina (PONTES DE MirandA, Tratado, v. 4, p. 206 e 207) :

"Tempo Para a Alegação da Nulidade. - Sempre que regra especial não há, que exija ação autônoma, a nulidade pode ser alegada a qualquer tempo do processo, ainda incidenter. Trato incidental diz-se o da matéria, quando não seja a do pedido na ação proposta, e, no tocante à nulidade, ainda quando a ação se refira a algum efeito que se pretenda ter sido produzido pelo ato jurídico nulo. A regra é não ser preciso propor-se a "ação" de nulidade, que é constitutiva negativa: basta alegar-se a nulidade, ou vê-la o juiz, ainda em ação de declaração."

"Quem Pode Alegar a Nulidade - O princípio da alegabilidade do nulo por aquele contra quem se querem efeitos é o que domina essa matéria. De modo que estão legitimados os que têm interesse no afastamento do pretendido efeito, sejam contratantes ou não, sucessores, ou simples atingidos pela eficácia que se pretende exista."

Com tal esclarecimento, não pode haver dúvida de que qualquer dos coobrigados é, na hipótese aventada, o "interessado" referido no texto legal, cabendo-lhe, a todo tempo ou fase processual, argüir a nulidade. 